\title{
Awareness \& Practice of Hand Hygiene among Medical Students of RIMS Ranchi, India
}

\author{
Dr. Dharmendra Kumar ${ }^{1}$, Dr.Ashok Kumar Dubey ${ }^{2}$ \\ ${ }^{1,2}$ Associate Professor, Department of Anatomy, Rajendra Institute of Medical Sciences ,Ranchi
}

\begin{abstract}
Objective: To find out the practice of personal hygiene and hand hygiene and correlation with its effects on health outcomes among medical students.

Methods: At Rajendra Institute of Medical Sciences, Ranchi over a period of 3 months. 200 students were selected on random basis from $2^{\text {nd }}, 6^{\text {th }} \& 8^{\text {th }}$ semesters. A pre-designed and pre-tested questionnaire was used to collect data from students, which was distributed to them and collected back. Anonymity was maintained. Data was assimilated in Microsoft Excel 2014 and analysed using SPSS 20 software.

Conclusions: Medical students are predisposed to a wide array of infections during dissections, microbiology and pathology practical classes and during bed side teaching while handling or examining the patients. All medical students are expected to practice standard personal hygiene practice. Universal compliance to personal hygiene among the medical students under study were not found in the current study
\end{abstract}

\section{Introduction}

Hand hygiene and personal hygiene are the primary measures for prevention of infectious diseases.. This is because enough scientific evidence supports the observation that if properly implemented, personal hygiene alone can significantly reduce the risk of cross transmission of infection in health care facilities. Proper personal hygiene practice of medical students is more important as they interact with patients during anatomical dissections, laboratory practical and clinical postings \& any time while providing health care. With these backgrounds, the current study was planned to find out the practice of personal hygiene and hand hygiene and correlation with its effects on health outcomes among students

\section{Materials \& Methodology}

It is a descriptive epidemiological study, cross-sectional in design, conducted at Rajendra Institute of Medical Sciences, Ranchi over a period of 3 months. 200 students were selected on random basis from $2^{\text {nd }}, 6^{\text {th }}$ $\& 8^{\text {th }}$ semesters. A pre-designed and pre-tested questionnaire was used to collect data from students, which was distributed to them and collected back. Anonymity was maintained. Data was assimilated in Microsoft Excel 2014 and analysed using SPSS 20 software

\section{Results.}

Altogether 200 student participants were there in the study among which 80(40\%) were students of 2nd semester, $60(30 \%)$ were students of $6^{\text {th }}$ semester and $60(30 \%)$ were students of $8^{\text {th }}$ semester ..Overall $132(66 \%)$ were male and $68(34 \%)$ were female.. For the whole group of study participants $131(65.5 \%)$ stay in college hostel, 60(33\%) in rented house and $9(0.45 \%)$ in rented house.

\begin{tabular}{|l|l|l|l|l|}
\hline \multirow{2}{*}{ Student's profile } & $2^{\text {ND }}$ SEMESTER & $6^{\text {th }}$ SEMESTER & $8^{\text {th }}$ SEMESTER & TOTAL \\
\cline { 2 - 5 } & $\mathrm{N}=80$ & $\mathrm{~N}=60$ & $\mathrm{~N}=60$ & \\
\hline Gender & & & & \\
\hline Male & 54 & 37 & 41 & $132(66 \%)$ \\
\hline Female & 66 & 23 & 19 & $68(34 \%)$ \\
\hline Residential status & & & & $131(65.5 \%)$ \\
\hline College hostel & 23 & 52 & 56 & $60(33 \%)$ \\
\hline Rented house & 53 & 4 & 3 & $9(0.45 \%)$ \\
\hline Own house & 4 & 4 & 1 & \\
\hline
\end{tabular}

The habit of hand washing practice among students shows that 200(100\%) of students wash hands after going to toilet , 188(94\%) students wash hands before touching or taking food ,189(94\%) of students wash 
hands after practical classes or clinics. Use of cleansing material for washing hands varied among students $29(14.5 \%)$ students use plain water ,117 (58.5\%) use soap or detergent water and 54 (27\%) students were using antiseptic solution or hand sanitizer.

\begin{tabular}{|l|l|l|l|l|}
\hline & $2^{\text {ND }}$ SEMESTER & $6^{\text {TH }}$ SEMESTER & 8. $^{\text {th }}$ SEMESTER & \\
\hline & & & & \\
\hline Hand washing practice & & & & \\
\hline After going to toilet & 80 & 60 & 60 & $200(100 \%)$ \\
\hline Before touching/ taking food & 4 & 56 & 88 & $188(94 \%)$ \\
\hline $\begin{array}{l}\text { After clinical / practica } \\
\text { classes }\end{array}$ & 78 & 54 & 57 & $189(94 \%)$ \\
\hline Use of cleansing materials & & & & \\
\hline Plain water & 12 & 8 & 9 & $29(14.5 \%)$ \\
\hline Soap or detergent water & 54 & 33 & 30 & $117(58.5 \%)$ \\
\hline $\begin{array}{l}\text { Antiseptic, Sanitizer \&Other } \\
\text { materials }\end{array}$ & 14 & 19 & 21 & $54(27 \%)$ \\
\hline
\end{tabular}

Awareness and knowledge of students was assessed and $142(71 \%)$ students were aware of various nosocomial infections , 196(98\%) students were aware of water borne diseases, 184(92\%) students were aware about importance of hand hygiene , 77(38.5\%) students were aware of proper hand washing technique , 41(20.5\%) students knew or read about WHO guidelines on hand hygiene. All students 200(100\%) were aware of drinking water safety and its methods

\begin{tabular}{|c|c|c|c|c|}
\hline \multirow[t]{2}{*}{ Awareness } & $2^{\mathrm{ND}}$ SEMESTER & $6^{\text {th }}$ SEMESTER & $8^{\text {th }}$ SEMESTER & TOTAL \\
\hline & $\mathrm{N}=80$ & $\mathrm{~N}=60$ & $\mathrm{~N}=60$ & \\
\hline Nosocomial infections & 22 & 60 & 60 & $142(71 \%)$ \\
\hline Water borne diseases & 76 & 60 & 60 & 196(98\%) \\
\hline Hand hygiene & 64 & 60 & 60 & $184(92 \%)$ \\
\hline Hand washing technique & 6 & 24 & 47 & $77(38.5 \%)$ \\
\hline $\begin{array}{l}\text { WHO guidelines on hand } \\
\text { hygiene }\end{array}$ & 4 & 13 & 24 & $41(20.5 \%)$ \\
\hline Drinking water safety & 80 & 60 & 60 & $200(100 \%)$ \\
\hline
\end{tabular}

Symptoms which may be manifested by poor hand hygiene was assessed for past 6 months, 61(30.5\%) students had one or more episodes of diarrhoea, 6(3\%) students had dysentery , 39(19.5\%) students had one or more episodes of vomiting. $4(2 \%)$ had skin infections .10(5\%) students had UTI

\begin{tabular}{|c|c|c|c|c|}
\hline \multirow[t]{2}{*}{$\begin{array}{l}\text { Symptoms } \\
\text { Preceding } 6 \text { Months }\end{array}$} & In & $6^{\text {th }}$ SEMESTER & $8^{\text {th }}$ SEMESTER & TOTAL \\
\hline & $\mathrm{N}=80$ & $\mathrm{~N}=60$ & $\mathrm{~N}=60$ & \\
\hline Diarrhoea & 23 & 17 & 21 & $61(30.5 \%)$ \\
\hline Dysentery & 3 & 1 & 2 & $6(3.3 \%)$ \\
\hline Vomiting & 12 & 14 & 13 & $39(19.5 \%)$ \\
\hline Skin Infections & 2 & 1 & 1 & $4(2 \%)$ \\
\hline URTI/LRTI & 24 & 11 & 39 & $74(37 \%)$ \\
\hline UTI & 4 & 2 & 4 & $10(5 \%)$ \\
\hline
\end{tabular}

\section{Discussion}

In the study of Kadi A and Salati SA, among 60 medical students $60 \%$ and $40 \%$. The average awareness regarding the positive indications of hand hygiene was $56 \%$. Rests of the $44 \%$ of students were either 
not sure or unaware of the indications of hygiene. Only $29 \%$ of students were able to identify all the five indications for hand hygiene. There was no significant difference between two genders. In the present study also, $100 \%$ students has habit of washing hands after going to toilet, 94\% has practice hand washing before taking food and 94\% wash hands after attending clinical and practical classes.Mohesh G and Dandapani A showed in their study, Four hundred and forty students were randomly selected from each year of MBBS course and surveyed with a pretested structured questionnaire. 96 reported that they are aware of hand hygiene practices, but 3/4 th of them said that they had no formal training on the same. 50\% of them accepted that, hand hygiene practices before and after handling a patient will prevent health care associated infections.. Girls differed from boys in their opinions on hand hygiene, they practiced hand hygiene better than boys.

Mobashr KA and Ibrahim MA showed in their study, most of the medical students performed hand hygiene. Females had better attitudes than males. The study showed that the overall average of medical student's knowledge about health care associated infection was 68.34\%.Ayub A et al. showed in their study, only $31.25 \%$ medical students always followed hand hygiene procedure. Complete knowledge about hygiene and infection control procedures present only among $77.5 \%$ of students.

\section{Conclusion}

Medical students are predisposed to a wide array of infections during dissections ,microbiology and pathology practical classes and during bed side teaching while handling or examining the patients. All medical students are expected to practice standard personal hygiene practice. Universal compliance to personal hygiene among the medical students under study were not found in the current study"Personal Hygiene" topic is included in the medical curriculum, it should be given emphasis so that student understand the importance of it and convert it in practice in their daily life. The improved understanding of infection control and personal hygiene among students is expected to play a major role in curbing disease transmission when the students pass out and join the healthcare work force in future

\section{Refrences}

[1]. K. Park, Park $\quad$ 's Textbook of Preventive and Social Medicine ( Jabalpur. India: M/S BanarsidesBhalnot, 2011) 799.

[2]. P.Mathur, Hand hygiene : Back to the basics of infection control, Indian Journal of Med Res, 134, November 2011, 611-20.

[3]. A.Kadi, S. A.Salati, Hand hygiene practices among medical students, Interdisciplinary perspectives on infectious diseases, 2012, August 2012, 1-6.

[4]. G.Mohesh, A.Dandapani, Knowledge, attitude and practice of hand hygiene among medical students - A questionnaire based survey, Unique Journal of medical and dental sciences,2(2), September 2014, 127-131.

[5]. K. A.Mobashr, M. A. Ibrahim, W. A. Hussein, Perceptions of medical students towards nosocomial infections at college of medicine- Babylon, Journal of Education and Practice,5(29), 2014, 73-84.

[6]. A.Ayub, A.Goyal, A.Kotwal, A. Kulkarni, A.Kotwal, A.Mahen, Infection control practices in health care : Teaching and learning requirements of medical undergraduates, Medical Journal Armed Forces India, 69, 2013, 107-112.

[7]. S. Usman, S. Bhat, S.Sargod, Oral health knowledge and behavior of clinical medical, dental and paramedical students in Mangalore, Journal of Oral Health Comm Dent, 1(3), 2007, 46-48. 